\title{
POST-the Pacific Ocean salmon tracking project
}

\section{POST, le projet de suivi du saumon du Pacifique}

\author{
David W. Welch ${ }^{\mathrm{a} *}$, George W. Boehlert ${ }^{\mathrm{b}}$, Bruce R. Ward ${ }^{\mathrm{c}}$ \\ ${ }^{a}$ Pacific Biological Station, Fisheries and Oceans Canada, Nanaimo, V9T 6N7, B.C. Canada \\ ${ }^{\mathrm{b}}$ Oregon State University, Hatfield Marine Science Center, 2030 SE Marine Science Dr., Newport, OR, 97365-5296, USA \\ ${ }^{\mathrm{c}}$ B.C. Fisheries Research and Development, 2204 Main Mall, University of British Columbia, Vancouver, V6T 1Z4, B.C. Canada
}

Received 29 November 2002; accepted 30 November 2002

\begin{abstract}
For most of history, the ocean has remained nearly opaque to study, and it has been difficult to understand where salmon or other marine animals go or how they use the ocean. This greatly limits the ability of oceanographers and fisheries biologists to improve the management of many marine resources. The technical and scientific basis now exists to track the ocean movements of individual marine fish for months or years at a time. In this article, we review how new technologies might be applied to salmon in particular. Our conclusion is that animals as small as juvenile Pacific salmon can be followed for months to years at sea, and thus over great distances. By identifying the migration pathways for individual salmon and specific populations of Pacific salmon, we can establish their ocean foraging grounds. We outline the approaches and initial results from the Census of Marine Life program pacific ocean salmon tracking (POST). The research program involves two distinct aspects: (1) the development of an acoustic array for tracking the movements of Pacific salmon during their shelf-resident phase of the life history and (2) the use of archival (data storage) tags to measure aspects of their local environment and to delineate their open ocean migration pathways off the shelf. We report on some of the preliminary findings from the first year of the field project using acoustic tags.
\end{abstract}

(C) 2002 Ifremer/CNRS/IRD/Éditions scientifiques et médicales Elsevier SAS. All rights reserved.

\section{Résumé}

L'étude de l'océan est récente et il a été difficile de comprendre vers où migraient les saumons et d'autres animaux marins et comment ils « utilisaient » l'océan. Ceci limite notre aptitude à optimiser l'utilisation des ressources marines. La base technique et scientifique existe maintenant pour suivre, durant des mois voire des années les déplacements individuels de poissons dans l'océan. Dans cet article, nous montrerons comment ces nouvelles techniques peuvent être appliquées, en particulier au saumon. Notre conclusion indiquera qu'il est possible d'appliquer cette approche aux juvéniles de saumon du Pacifique et ce à l'échelle du bassin et durant plusieurs années. En identifiant les parcours de migratoires à l'échelle de l'individu et de la population, nous pourrons définir les aires océaniques d'engraissement. Nous mettons également en lumière l'approche et les premiers résultats de pacific ocean salnon tracking (POST), volet du projet Recensement de la vie marine. Ce programme comprend deux aspects : (1) la mise au point d'un procédé acoustique pour suivre les migrations du saumon du Pacifique quand ils résident sur le plateau continental ; (2) l'utilisation de « marques » archivées pour définir l'environnement local et délimiter la migration dans l'océan du large. Enfin, nous présenterons les premières impressions issues d'une première année de mesures de terrain utilisant les marques acoustiques.

(C) 2002 Ifremer/CNRS/IRD/Éditions scientifiques et médicales Elsevier SAS. Tous droits réservés.

Keywords: Salmon; Archival tags; Acoustic tags; Biotelemetry; Migration

Mots clés: Saumon; Marques archivées; Marques acoustiques; Biotélémétrie; Migration

\footnotetext{
* Corresponding author.

E-mail address: welchd@pac.dfo-mpo.gc.ca (D.W. Welch).
} 


\section{Introduction}

Where do salmon go? What do they do when they get there? How do they return to spawn in their home rivers? How do changes in the ocean environment affect their survival? Underlying these questions is the belief that salmon may have "two zip codes", or postal addresses, homing not only back to their rivers of origin, but also to specific feeding grounds in the ocean. Given the remarkable ability of Pacific salmon to return precisely to the vicinity of their own birthplace (e.g. Quinn, 1993; Quinn et al., 1999), these feeding grounds and the ocean pathways taken to get to them may be as population-specific as their rivers of origin, but as yet undiscovered. Accepting the possibility that marine animals such as Pacific salmon may shuttle between two postal addresses, their well-defined and long accepted freshwater spawning grounds, and their as yet undiscovered ocean migration pathways and marine feeding grounds, project "POST" was initiated.

The marine ecology of the North Pacific, particularly as applied to salmon, can be broken down into three ecological zones-the pelagic offshore overlying the abyssal plains (water depths of 3-4 km), the continental shelf (depths $\leq 200 \mathrm{~m}$ ), and the narrow continental slope region separating the two (depths ranging from $200 \mathrm{~m}$ at the shelf edge down to the abyssal plain). Often, groups of pelagic and planktonic organisms may be broken into offshore and coastal assemblages with the transition near the shelf break (Richardson et al., 1980; McGowan, 1993) or even closer to shore (Peterson et al., 1979). As water depths increase rapidly in the slope region, with an average gradient of just over $4^{\circ}$ in most regions of the world (Emery, 1980, Khan, 2000; Wiseman and Ovey, 1953), the $1000 \mathrm{~m}$ isobath is typically found only some $10-11 \mathrm{~km}$ seaward of the edge of the continental shelf. Shoreward of the shelf edge, the shallow shelf region can be very wide in many parts of the world's oceans. However, off the west coast of North and South America, the shelf is frequently only $15-30 \mathrm{~km}$ wide, making this area one of the narrowest (and longest) continental margins in the world. Since most marine animals consistently occupy specific depth zones, efforts to monitor the movements of animals remaining in the shelf or slope water regions are perhaps simplest to implement off the west coast of the Americas. Partly for this reason, the shelf tracking component of POST is focused in the Pacific.

Pacific salmon provide an excellent prototype organism for studying marine movements because there is a great social and economic interest in these animals and they occupy both shelf and offshore regions of the North Pacific for extended periods of time. The oceanic phase of the life history is also vastly understudied relative to the great body of freshwater research undertaken in the past. In general, the migratory movements of all species of juvenile Pacific salmon (excluding steelhead) are confined to the shelf-slope region for many months. Some stocks eventually migrate to the open ocean after reaching the Aleutians, while other stocks appear to take up permanent residence on the shelf (Hartt and Dell, 1986; Welch, in prep.). Once past their first year of life in the ocean, most species of Pacific salmon take up a pelagic existence in the offshore, while two species (coho and chinook) appear to have both shelf-resident and offshore variants (Groot and Margolis, 1991).

As the marine movements of individual salmon are poorly understood, a concerted research program using new electronic tagging technology offers the opportunity to make major breakthroughs in our understanding of how salmon use the ocean: where they go, how they use the structure of the ocean environment to accomplish these migrations, and what ocean conditions they experience when they reach their marine feeding grounds. POST is intended to address a number of major research problems for Pacific salmon; resolution of these questions would likely contribute significantly to the improved management and conservation of Pacific salmon:

- Establish whether Pacific salmon have "two postal codes", adding to the marine life history information that is already widely known and accepted about the freshwater phase of the life history

- Understand how Pacific salmon use the ocean environment

$\circ$ Identify distribution and habitat use by key species and life stages

- Identify important oceanic features and critical habitats - Do salmon respond to sharp thermal boundaries?

- Do salmon depend upon specific ocean structural features?

- Do salmon use common migration pathways?

- Establish latitudinal patterns of movement and habitat utilization by salmon

- Examine the coupling between biology and the physical environment-how do different species respond to changing ocean conditions?

- Determine how longer-term changes in ocean conditions relate to changes in fish condition, growth, survival, and distribution

\subsection{Classes of electronic tags}

Animals migrating in the Pacific Ocean can be broken into two broad classes: those using the continental shelf as a migration corridor (salmon in their first year of ocean life, many whales, sea lions, and groundfish), and those that use the open ocean (Pacific salmon at older ages, tunas, elephant seals, marine turtles). For air-breathing vertebrates (marine mammals, sea turtles) which remain at the surface long enough for satellite communications, animals can be tracked using standard position-fixing methods based on radio signals and satellites. However, for the majority of animals, such as salmon, that are small or remain submerged in seawater, the ocean remains opaque, and we have very little real sense of where these animals go or how they use the ocean. The technology for monitoring salmonids in the 


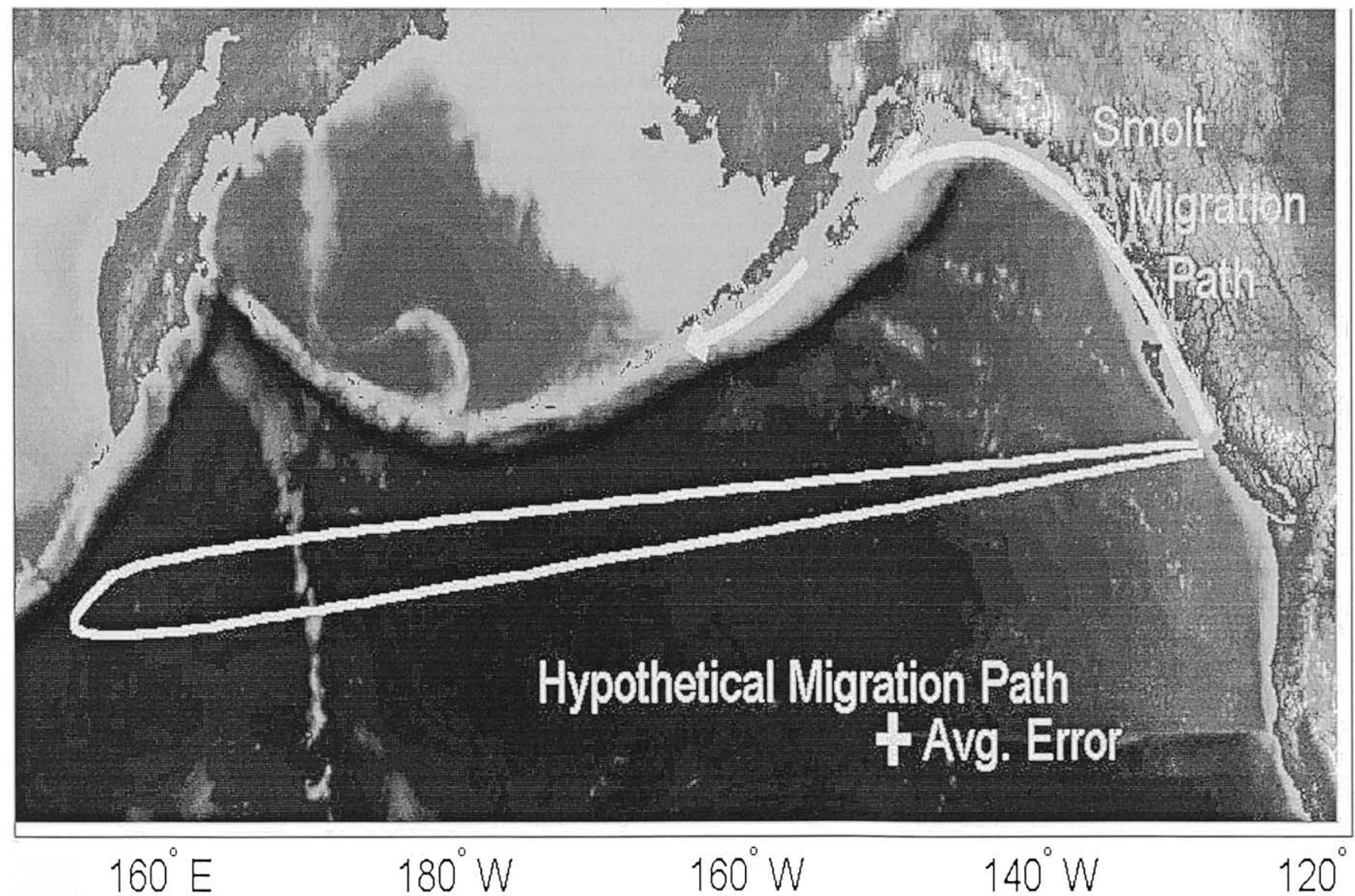

Fig. 1. Comparison of the known accuracy of daily position estimates from archival tags (Welch and Eveson, 1999, 2001) with a hypothetical path of salmon migration. The "+" shows the size of the average error in calculated daily position $( \pm 1 \mathrm{SD})$. For contrast, the shelf-oriented migration of most salmon smolts is also shown. The shelf migration pathway is too narrow to be resolved using archival tag technology, necessitating the use of the acoustic tracking technology described in the text.

continental shelf and offshore realms is different, and we describe the plans for the studies separately.

\subsection{Offshore-archival tags}

Archival tags are internally recording electronic tags which can measure and store a wide variety of environmental data that detail the ocean environment that the salmon move through and use for foraging. The most frequent types of information recorded typically include ambient temperature or depth, but can also include light-based estimates of daily position. More exotic sensors that can provide information such as heart rate, tail beat frequency, or swimming speed are also either on the horizon or are now commercially available (review by Arnold and Dewar, 2002).

In the offshore, larger Pacific salmon $(>35 \mathrm{~cm})$ can be tagged with the new generation of archival tags (Welch and Eveson, 1999). These tags allow an estimate of geoposition to be achieved to an accuracy of $0.5^{\circ}$ of latitude and $0.25^{\circ}$ in longitude, or a mean error in position of about $40-50 \mathrm{~km}$ (Welch and Eveson, 2001). Positional estimates can be further refined by comparison with oceanographic measure- ments, but improvements in position fixing beyond this level are unlikely in the near future.

Accuracy on this scale is sufficient to track the basinscale movements of animals in the open Pacific (Fig. 1). (The Pacific Ocean spans about $95^{\circ}$ east to west, and roughly $40^{\circ}$ north to south, depending upon the area of interest.) These tags also allow detailed recordings of vertical movements and the water temperatures occupied by the tagged animals. The use of geoposition-capable archival tags in the offshore would reveal the large-scale migrations of open ocean salmon, and is of major interest for both "pure science" reasons, and as a basis for improving the management of highly migratory pelagic species.

Most species of salmon only become large enough to successfully tag in the late spring of their last year in the ocean, some 4-6 months prior to return. As archival tags are internally recording devices, they must be recovered from a tagged fish, and then returned (typically, by a fisherman) to the laboratory. The proportion of archival tags returned will therefore depend on the fishing effort, mortality and tag shedding experienced after tagging, and the degree to which recovered tags are returned (Walker et al., 2000). In large 
fish, such as tunas, sharks or mammals, "pop-up" archival tags can be designed to release from a tagged animal and transmit some or all of the recorded information via satellite (Block et al., 1998; Lutcavage et al., 1999). However, the current size of these tags makes their use on salmon infeasible. As a result, the cost and capability of these tags must then be balanced against the expected recovery rate; expensive archival tags will only be applied in situations where their expected recovery rate will be high.

\subsection{Button tags}

For the foreseeable future, it is likely that archival tags will need to be recovered from recaptured salmon. Due to the high losses that juvenile salmon experience after entering the ocean (often only $1-10 \%$ surviving to return), archival tags applied to juvenile salmon must be both small and low cost, to make the cost of studies economically feasible. One class of tags being developed for use within POST for use on juvenile salmon is the "i-Button" tag, a small and low-cost tag that would record temperature only and perhaps cost on the order of \$20 US per tag. These tags can be made at low cost because they are produced commercially in large numbers for the refrigeration industry, to provide a record of the temperature history of transported goods. The POST component of this project will focus on developing a waterproof case for the tag, and has applied these tags in an initial field trial.

\subsection{Continental shelves-acoustic tags}

Because to the limited spatial resolution of archival tags, it seems unlikely that archival tags will ever be of much use for determining onshore-offshore position on continental shelves, since the width of these shelves is often smaller than the best spatial resolution currently possible. In the shelf-slope environment, however, the limited spatial scale can be used to advantage, because animals tagged with active tags capable of detection from nearby sensors will provide a useful position fix.

Acoustic tags small enough to be carried by young salmon cannot store environmental information for later transmission; so a picture of the movement of tagged Pacific salmon and their environmental conditions needs to be built up by having the position and current environmental conditions for individual salmon logged by multiple receivers. Acoustic tags send out information on the identity of the tagged animal and (for some types of tags) currently experienced environmental conditions (depth or temperature).

Self-contained submersible acoustic receivers capable of detecting and logging the movements of a tagged juvenile are now available that can operate autonomously for over a year underwater (e.g. Voegeli et al., 1998; Lacroix and Voegeli, 2000). These recent technological advances build upon the pioneering efforts of Lacroix and McCurdy (1996), who demonstrated the first example of how such a technology can be used to track the movements of young salmon in seawater. Although these early acoustic tags and receivers were much larger and more short-lived than recent equipment, these efforts provide the first example of how an autonomous acoustic tracking system could be used to trace the movements of the youngest and most vulnerable life history stages in the ocean. An autonomous array allows the movement patterns of individual animals to be reconstructed, essentially by "connecting the dots": knowing the date and time an individual is heard in the vicinity of each acoustic receiver, speed and distance between each pair of receivers can be determined; in situ environmental conditions can be estimated from regional data which can be matched with the presence or absence of a tagged animal.

Recently developed technology offers the prospect of putting out many long-lived low-cost acoustic receivers on the seafloor, in a series of detection lines which can act as a grid over which thousands of individually identifiable tagged animals might move at will, with their movements passively recorded by the seabed array (Fig. 2). As the detection technology is relatively low cost, the possibility of a continental scale acoustic tracking array for the shelf and slope regions is economically feasible.

Acoustic tags now offer lifetimes of 4.5 months to several years (e.g. Lacroix and Voegeli, 2000) and experimental studies demonstrate that they can be successfully implanted into salmon smolts as small as $10.5 \mathrm{~cm}$ and retained long-term (Welch et al., in press); the possibility now exists to tag and track the movements of many animals for most of their life cycle. By building up a dense array of low-cost receivers sited on the seabed, it is potentially possible to reconstruct the movement patterns in great detail. This is perhaps the most ambitious aspect of the POST project, to help demonstrate the feasibility of a continental scale acoustic tracking array on the entire continental shelf. Curiously, despite considerable recent interest in the possibility of seafloor observatories by the oceanographic community (e.g. National Research Council, 2000), almost all of the proposals to date have involved highly expensive networks in the deep ocean consisting of a relatively few nodes cabled to land. While such a network would provide a high bandwidth but relatively sparse network, project POST would provide the complement: a broadly distributed but low cost and low bandwidth acoustic tracking array that could be run off long-lived lithium batteries. In this paper, we focus on describing the fish tracking component, and defer most of the technical details of how the array would be constructed for later consideration.

\subsection{Continental shelf program}

The narrowness of the continental shelf off the West Coast of North America is ideal for a broad-scale monitoring program using acoustic tags for animals such as juvenile 


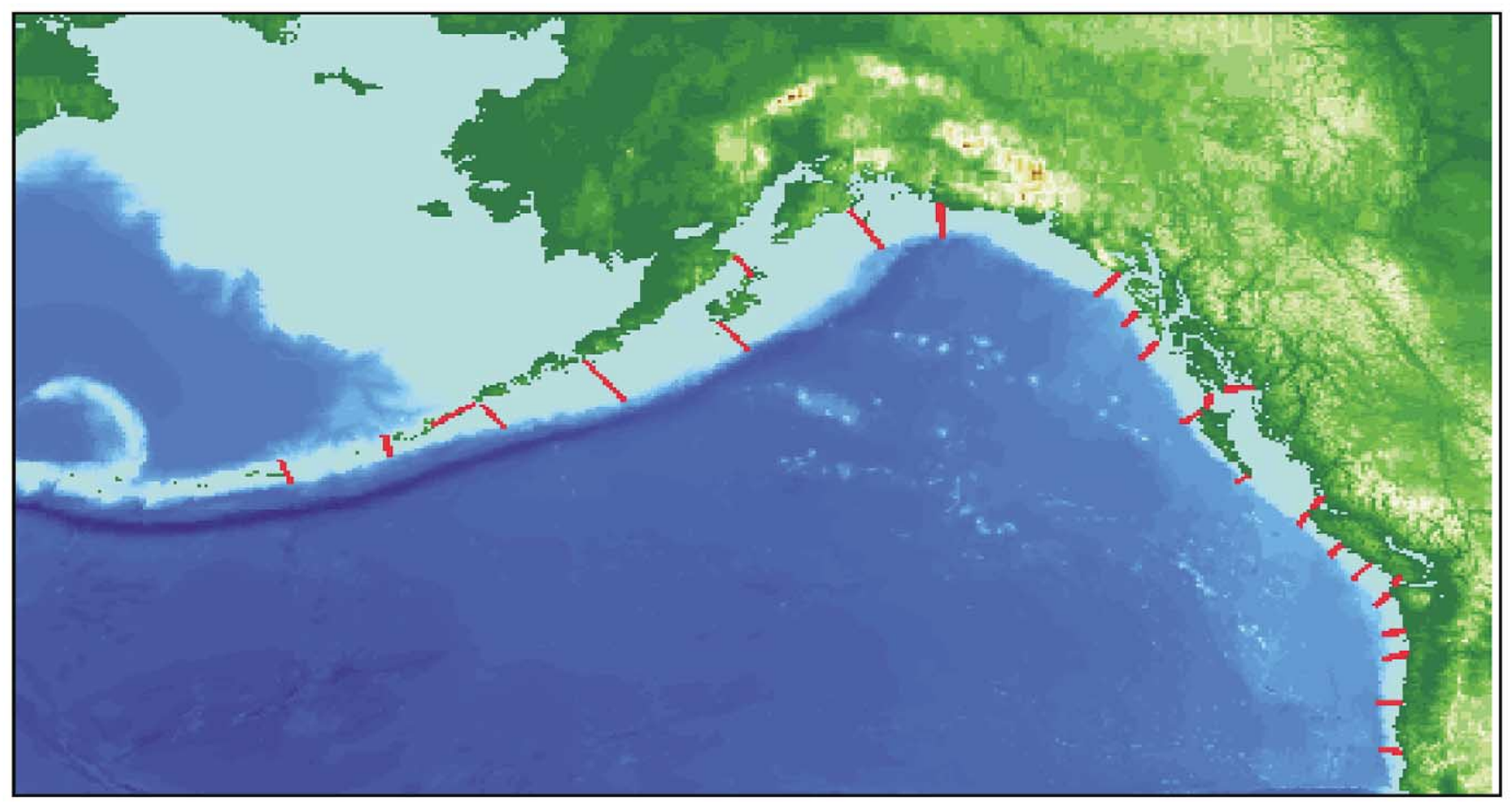

Fig. 2. Conceptual example of the monitoring network. Monitoring lines would be placed using islands and straits as bottlenecks to minimize the length of monitoring lines. For example, all tagged salmon migrating to or from the Fraser River or the East coast of Vancouver Island could be monitored with two short lines in Johnstone and Juan de Fuca Straits. Detection north or south of the straits would demonstrate which direction specific stocks move and their rates of migration. Each line would actually consist of a series of autonomous low-cost receivers, or nodes, placed so that their detection radii overlapped.

salmon that remain on the shelf. Recent developments in acoustic technology (e.g. Lacroix and Voegeli, 2000) allow reliable detection of uniquely identifiable sonic tags using low-cost passive receivers $(\$ 1000$ per receiver). These receivers can detect sonic tags within an ca. 1-2 km diameter circle centered on the receiver (depending on the acoustic power of the tag), recording the date and time that individual tags are detected for a year or more, and having a recording capacity per receiver of 300,000 or more detections (about 800 per day, on average).

In principle, a series of autonomous receivers laid in a line across the shelf perpendicular to the long-shelf migration path of animals such as Pacific salmon would be capable of detecting and recording the movements of each individual passing over the detection line. By placing separate lines of cross-shelf receivers at appropriate spacing on the shelf, a detailed picture of the movement patterns of tagged animals would be possible (Fig. 3).

\subsection{Geometry of detection}

Simple calculations suggest that a staggered array of listening lines should be more effective than a few densely instrumented lines. This arrangement would also provide more information on movement (speed, direction) between each pair of detection points (nodes). For these reasons, it is most fruitful to consider developing an extensive array of multiple lines, each consisting of low-cost acoustic listening nodes. Such a design would compensate for the possibility that if the local environmental conditions allow a tagged fish to pass undetected at one listening line, then subsequent independent listening lines in the array will allow further chances to detect an animal's passage.

To consider the geometry of the detection array, imagine a tagged animal swimming in a straight line somewhere in the vicinity of an acoustic receiver (Fig. 3). The animal will remain within the detection radius of the receiver, $r$, for a chord length of $L(x)$ meters, where

$$
\mathrm{L}(\mathrm{x})=2 \sqrt{r^{2}-x^{2}}
$$

Here $x$ is defined as the minimum distance from a receiver. The expected value of $L(x)$ is

$$
\bar{L}=E(L(x))=\frac{1}{2 r} \int_{-r}^{+r} 2\left(r^{2}-x^{2}\right)^{1 / 2} \mathrm{~d} x
$$

or,

$$
\bar{L}=\frac{1}{2 r}\left[x\left(r^{2}-x^{2}\right)^{1 / 2}+r^{2} \sin ^{-1}(x / r)\right]_{-r}^{+r}
$$

which reduces to:

$$
\bar{L}=\frac{\pi}{2} r .
$$

In general, a migrating animal which swims within range of an acoustic receiver will have equal probability of being located at any distance $x$ from the receiver. Thus, on 


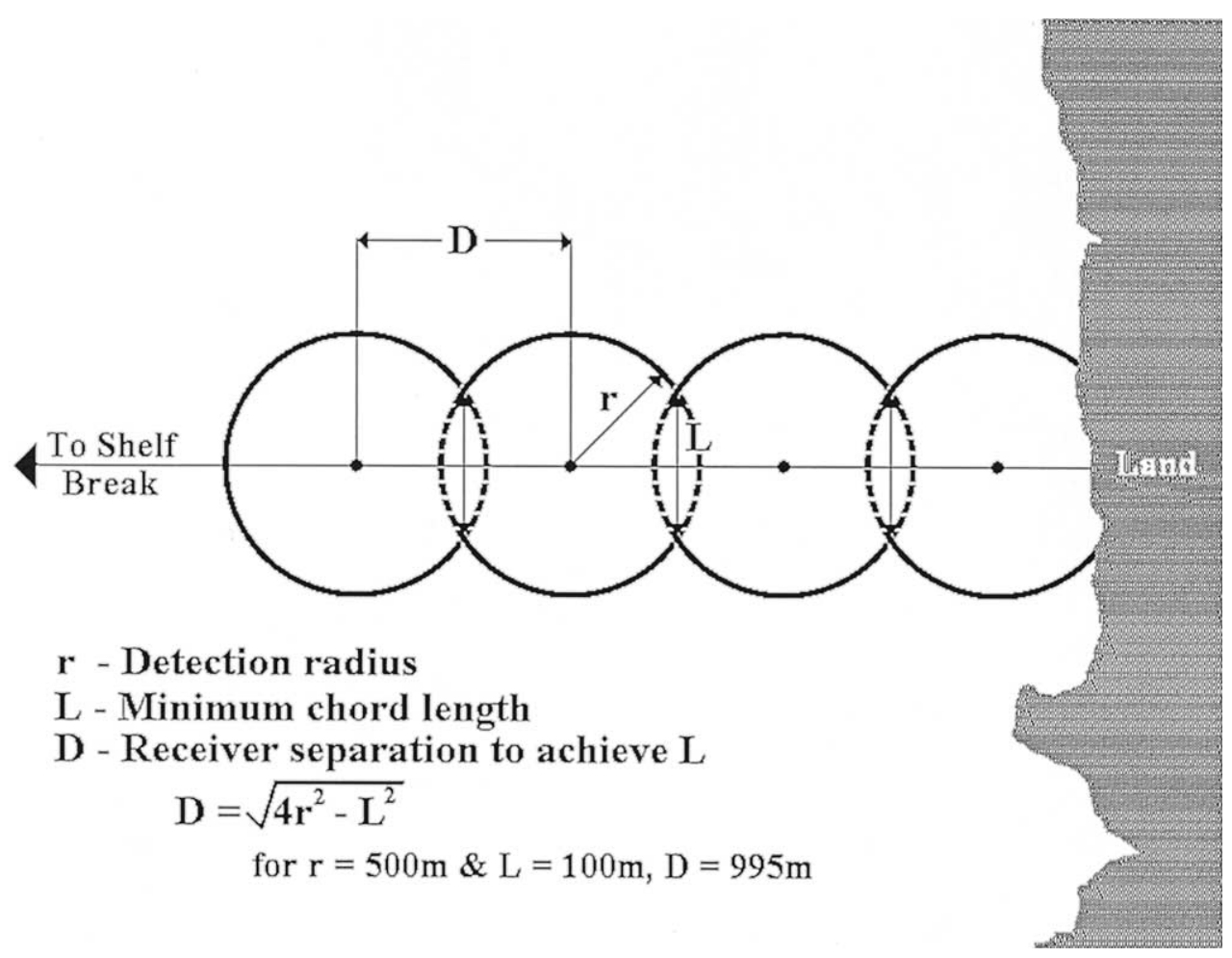

Fig. 3. Conceptual example of the cross-shelf monitoring array. The basic design goal is to determine the detection radius, $r$, at which an acoustically tagged animal can be identified under different oceanographic conditions. Knowing $r$, it is possible to determine the spatial separation, $D$, for the receivers to ensure that an animal crossing the array at right angles has a high probability of being detected. For a salmon smolt traveling at $15 \mathrm{~cm} / \mathrm{s}$, assuming that the minimum chord length is $L=100 \mathrm{~m}$ in the example given results in the animal traveling within the detection zone for a minimum of $11 \mathrm{~min}$.

average, an animal swimming in a straight line which is known to cross into the detection zone of a receiver will remain within detection distance for an expected time period of

$$
\bar{L} / s \approx \frac{\pi r}{2 s}
$$

min, where $\bar{L}$ is the average chord length, and $s$ is the swimming speed. For an animal crossing a detection line consisting of multiple receivers, the minimum distance that the animal can swim while remaining within the detection zone is located at the half-separation distance of the receivers, $D / 2$ (Fig. 3). The half-separation distance $D$ is surprisingly close to the maximum detection radius $r$; if we assume that $r=500 \mathrm{~m}$, and requires that $L_{\min }=100 \mathrm{~m}$, then this requires that the receivers be spaced at $D=995 \mathrm{~m}$; given the errors inherent in positioning receivers at sea and the changes in detection ranges under different weather conditions, then specifying a receiver spacing of $\sim 2 r$ or 1 $\mathrm{km}$ seems quite reasonable.

Work is currently underway to precisely characterize the exact detection distances in river, estuary (i.e. river mouth), and continental shelf waters, and thus to determine the receiver geometry for a single acoustic detection line across the continental shelf (Welch, unpublished). To date, this work suggests that the receiver can detect these low acoustic power output (and therefore long-lived) acoustic tags from distances of ca. $r=400-500 \mathrm{~m}$, and that tags with high acoustic power would have a detection range of ca. $1000 \mathrm{~m}$. As the shelf on the West Coast is usually less than $20 \mathrm{~km}$ wide, a string of 30 receivers laid across the shelf and down the upper slope region should be capable of detecting most animals on the shelf and slope which cross each detection line.

The costs of developing a broad-scale acoustic array are surprisingly modest. The current generation of receivers are commercially available for $\$ 1000$ US; taking into account the need for additional infrastructure to place the receivers on the seabed and recover the data, it may be possible to place and maintain each listening node for perhaps $\$ 5000$. As a result, this leads to an approximate cost for a single monitoring line on the order of $\$ 150,000$; thus for roughly three million dollars in capital costs, a network of 20 or so acoustic listening lines could be deployed that would stretch from California to the Aleutian islands (Fig. 2). Such a network would be capable of detecting individual animals as they crossed the monitoring lines. Overall costs for operating the array would need to include the costs of operating ships to deploy the seabed nodes and periodically upload the stored data, as well as the costs of tagging live animals, so would be significantly higher than just the capital costs; however, even at a final cost of 3-4 times the capital costs, the array would be surprisingly economical to operate. 
The smallest uniquely identifiable acoustic tags operating at frequencies useful for detection at hundreds of meters are capable of being surgically implanted into salmon smolts as small as $10.5 \mathrm{~cm}$ and retained for months or years (Welch et al., in press). As these tags have operational lifetimes of ca. 4.5 months, and slightly larger tags have lifespans of years, it is potentially possible to expect to tag young salmon in-river or on the shelf and be able to follow their movements during the first summer and fall, and potentially for the rest of their life history if longer-lived tags are used. The shelf component of project POST will focus on defining a "proof of principle" experiment to demonstrate the validity of putting into place such a network.

Such a monitoring framework would provide the basis for tracking any animal present on the continental shelf that was tagged with a uniquely identifiable sonic tag: smolts, immature shelf-resident salmon stocks in their second or third year of life, or even whales and other marine mammals. A wide complement of other marine fish could also be detected by such a monitoring network, providing the possibility of building broad support for the monitoring network and spreading costs by monitoring the movements of other high-valued fish such as halibut, sablefish, Pacific hake, and Pacific mackerel, as well as other important biological components of the ecosystem, such as whales, seals, or sharks.

The advantage of a fixed coastal array is that the geographic position of each array element is known with precision, so the detection of uniquely tagged animals by the array elements allows reconstruction of the coastal movements (direction and rate of movement between array elements, and time of occurrence in specific regions of the coast). Alternative systems generally require the recovery of the tag from the animal; this means that many more tags must be used than will be recovered. The great advantage of a fixed array is that recovery of tagged animals is not required, and many species might be simultaneously studied by the same array.

In addition, because of the large number of unique tag codes than can be tracked simultaneously, studies could potentially involve many hundreds or even thousands of tagged animals. This would allow long-term comparison of marine survival between different populations of salmon, e.g. as well as a comparison of the migration pathways and feeding grounds for the populations.

\section{Pilot project}

The goal of POST is to move in chronological sequence through three major stages: (a) planning, (b) pilot, and then on to (c) a major international program. However, prior to the start of the major pilot project, a demonstration of the feasibility of the methods is required even within the planning phase.
Archival tagging of most species of Pacific salmon will generally require tagging the animals at sea because the large size of these tags relative to young salmon precludes their use before the salmon have spent several months at sea feeding and growing (see, for example, Boehlert, 1997; Walker et al., 2000; Tanaka et al., 2000). This involves a significant cost for ship time and precludes studying the migration during the months prior to tagging.

Steelhead are an exception. A significant proportion (termed kelts) survive spawning, leaving their natal rivers in May as large animals capable of carrying an archival tag. They then return to spawn in the same river 8-11 months later (December), with survival rates that vary from $10 \%$ to $90 \%$ (B. Ward, data on file). Archival tags can be applied in freshwater to large steelhead kelts after spawning, and the entire migration track out to sea and back to the natal river can then determined for a significant proportion of these tagged animals (Fig. 4).

By double-tagging kelts with acoustic and archival tags, it is possible to develop some measurements on rates and direction of movements in the near coastal environment where the resolution of archival tags is insufficient. Unlike archival tags, which are too large to be used on smolts, acoustic tags can also be used on smolts. Since deployment of a full coastal array will require information on where salmon are migrating relative to the shore, we chose in 2001 to implant acoustic tags into steelhead smolts at the same time that the kelts are double-tagged, in order to gain some short-term information on the near-shore movements of the smolts immediately after ocean entry. An initial trial project was therefore run in 2001 to test the use of acoustic technology for developing a subsequent study. These initial measurements were intended to provide the basis for designing the full test study in the spring of 2002, which is planned for British Columbia and Alaska.

The British Columbia study in 2002 will be focused on steelhead from two adjacent river watersheds (Keogh and Waukwass; described in Ward et al., in press), whose rivers empty into the eastern and western coasts of Vancouver Island (Fig. 5). Despite their geographic proximity (the watersheds are adjacent to one another on the same mountain), the marine survival of smolts from all rivers on the eastern side of Vancouver Island is much lower than that of steelhead smolts exiting to the west coast of Vancouver Island (Smith et al., 2000; Ward, 2000; Welch et al., 2000). This difference may have a genetic basis, with steelhead from the Keogh and Waukwass taking different marine migration routes and therefore being exposed to different oceanographic regions.

In 2001, a total of 15 receivers were deployed near the Keogh R site. One receiver was placed in a small freshwater pool in the Keogh R, just above the tide line. Since the pool was only $20 \mathrm{~m}$ across, and the tags were programmed to transmit at a mean interval of $60 \mathrm{~s}$, it was recognized that rapidly moving smolts would likely not be detected while within the pool. In the ocean, the partial array was com- 


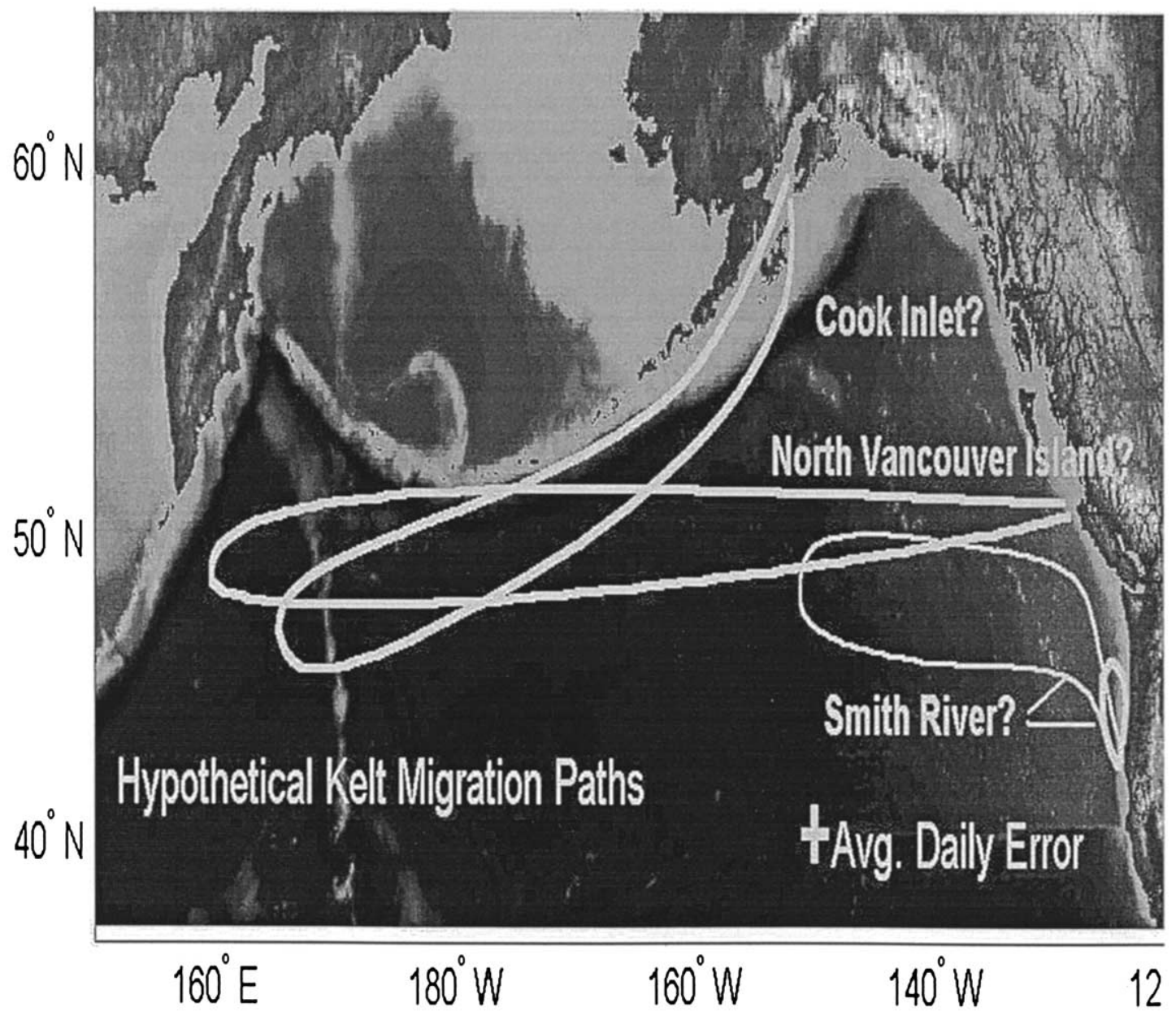

Fig. 4. Hypothetical migration pathways for steelhead kelts from the three study sites planned for 2002 (California, British Columbia, and Alaska). These pathways are based on conjecture, as direct work of the nature proposed here has never been performed. The archival tagging component of this project is intended to provide clear resolution of the pathways.

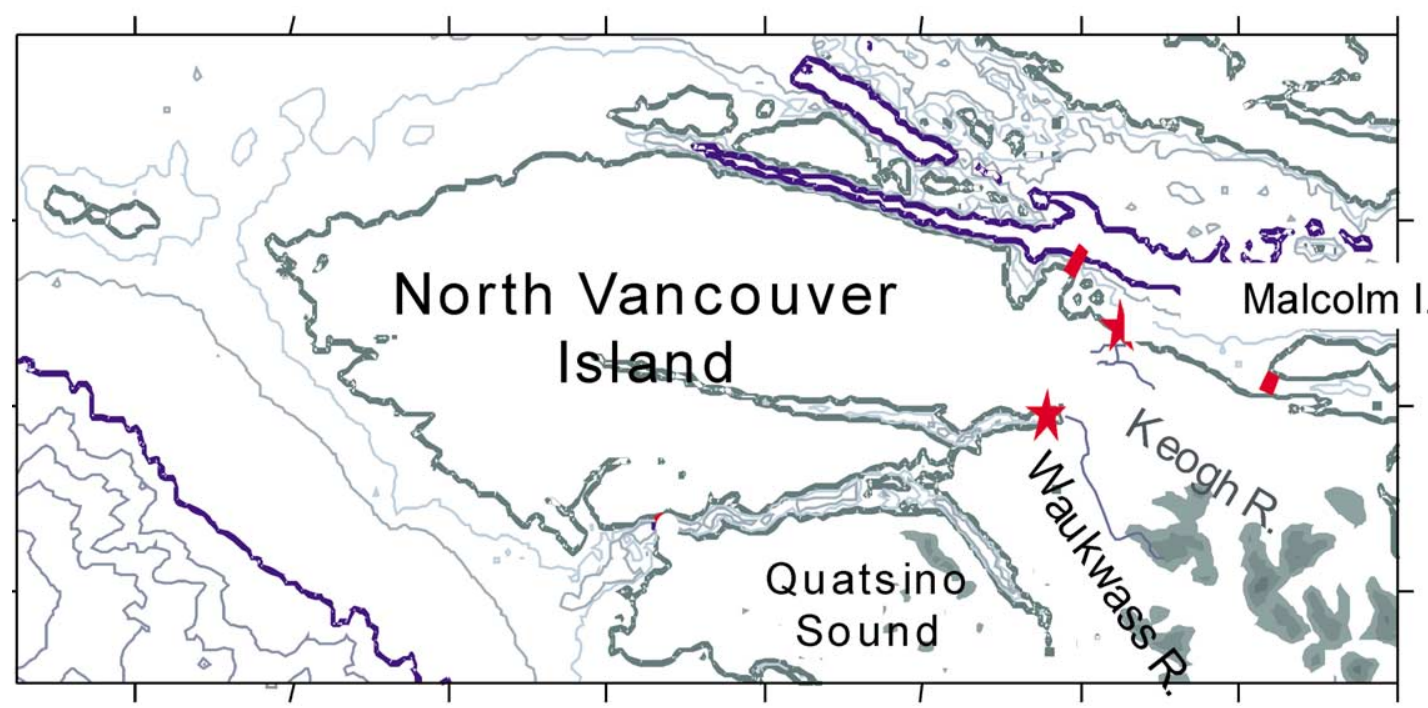

Fig. 5. Location of the proposed British Columbia CoML study site. The steelhead from East and West Coasts of Vancouver Island have very different marine survivals. Acoustic receivers will be deployed near the mouth of the two rivers to detect the time of ocean entry and the proportion of tagged smolts and kelts that survive to the ocean (stars). (These receivers will also detect the presence and measure the time of return for acoustically tagged kelts in the following winter.) In 2001, partial acoustic detection arrays consisting of two lines located north and south of the Keogh River mouth measured initial rates of migration. 


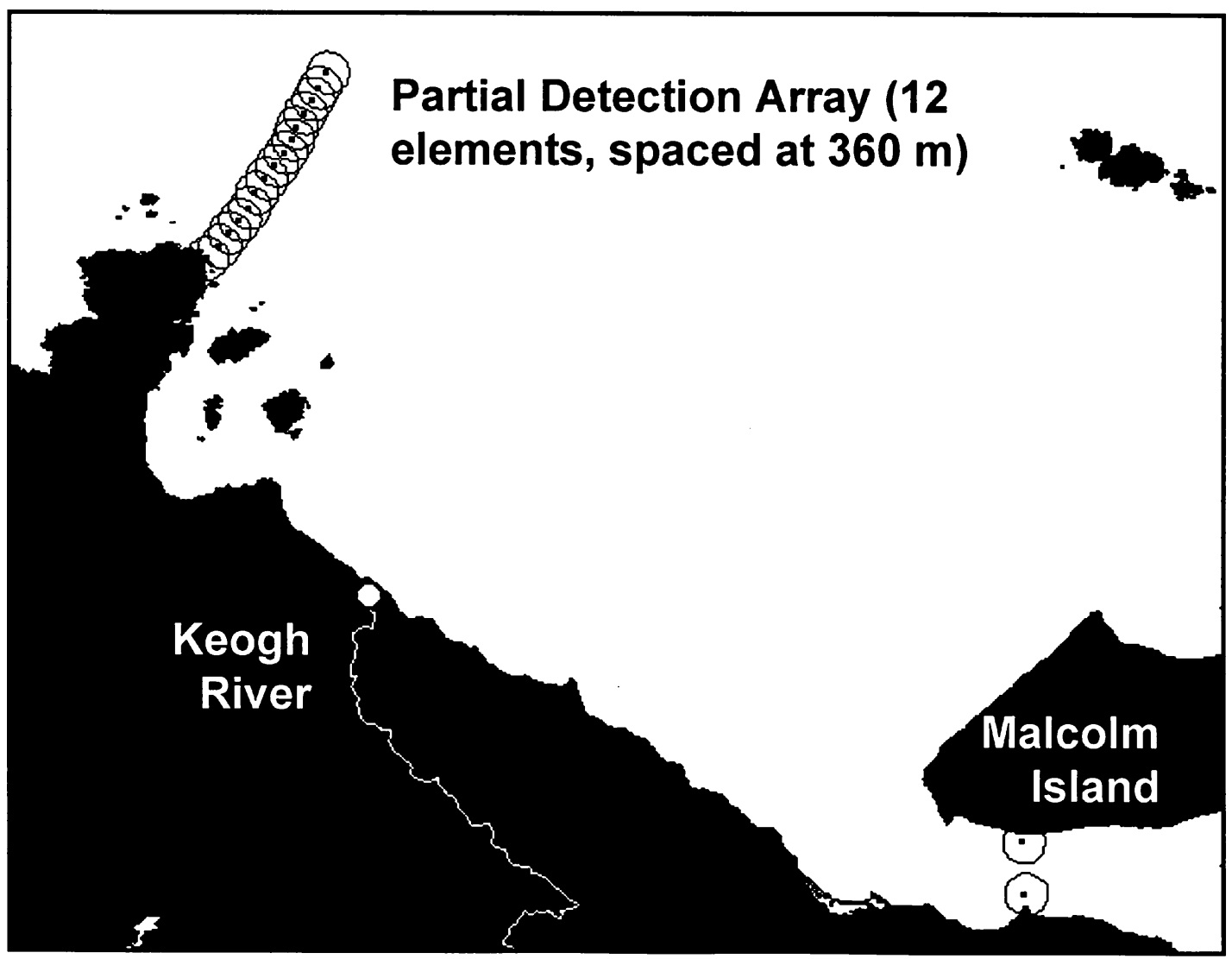

Fig. 6. Close-up of the Keogh study site, showing the region to the north of the receiver at the Keogh R mouth (circle). The array to the north was deployed using a high density spacing of $360 \mathrm{~m}$ between acoustic receivers, because work to fully characterize the detection capabilities of the equipment had not been completed by the time of the pilot study. The partial acoustic array extended $4 \mathrm{~km}$ of the total $21 \mathrm{~km}$ to the mainland $\mathrm{BC}$ coast.

posed of a line of 12 receivers spaced $360 \mathrm{~m}$ apart on the seabed (to ensure full coverage between receivers) in a linear array ca. $10 \mathrm{~km}$ to the north of the Keogh $\mathrm{R}$ mouth and extending perpendicularly from near the Vancouver Island shoreline towards the British Columbia mainland, some $21 \mathrm{~km}$ distant (Fig. 6). To the south, two receivers were placed separately on the seabed near the opposite shores of the $1.2 \mathrm{~km}$ wide channel between Vancouver Island and Malcolm Island. (The limited number of receivers available precluded placement of a third receiver in the center of the channel, which would have been necessary to obtain full coverage.)

An important principle in the development of a continental scale array is that all of the equipment must eventually sit on the seabed and not involve surface floats that are vulnerable to vessel traffic or fishing activities. The deployment was thus planned to gain some experience with this principle. Both detection lines were placed on the seabed using a horizontal groundline, and vertical floats spaced 360 $\mathrm{m}$ apart were used to position the receivers about $0.5 \mathrm{~m}$ off the seabed. On the outer edge of the northern detection line, where a deep channel reached ca. $350 \mathrm{~m}$ depth, the length of the vertical float lines was increased to position the receivers at or above $200 \mathrm{~m}$. All equipment was placed on the bottom, out of sight, and was retrieved by triggering acoustic releases which brought the floats and the end of the groundlines up to the surface. The groundline was then retrieved using a chartered seine vessel. A commercial fishing vessel was used for the deployment both to develop involvement with the industry and to maintain the principle of using low-cost vessels for deploying the array.

\section{Results and discussion}

A total of 26 smolts were surgically implanted in 2001 with acoustic tags set to broadcast their serial number at an average transmission interval of $1 \mathrm{~min}$; smolts were tagged and released on 29 May (6), 6 June (7), 7 June (7) and 8 June (6). Implanted smolts averaged $19.4 \mathrm{~cm}$ fork length (range 15.4-23.4 cm), and were randomly selected from the migrating smolts captured each day at the Keogh River weir without respect to size. Insertion of these tags proved simple in these large smolts, and the majority were clearly capable of having been tagged with larger tags that would have had lifespans well beyond 1 year.

Smolts were implanted during the daytime at the weir and held until dusk to reduce predation from birds and mammals (chiefly eagles and river otters). They were then released to a pool just below the weir and about $200 \mathrm{~m}$ 


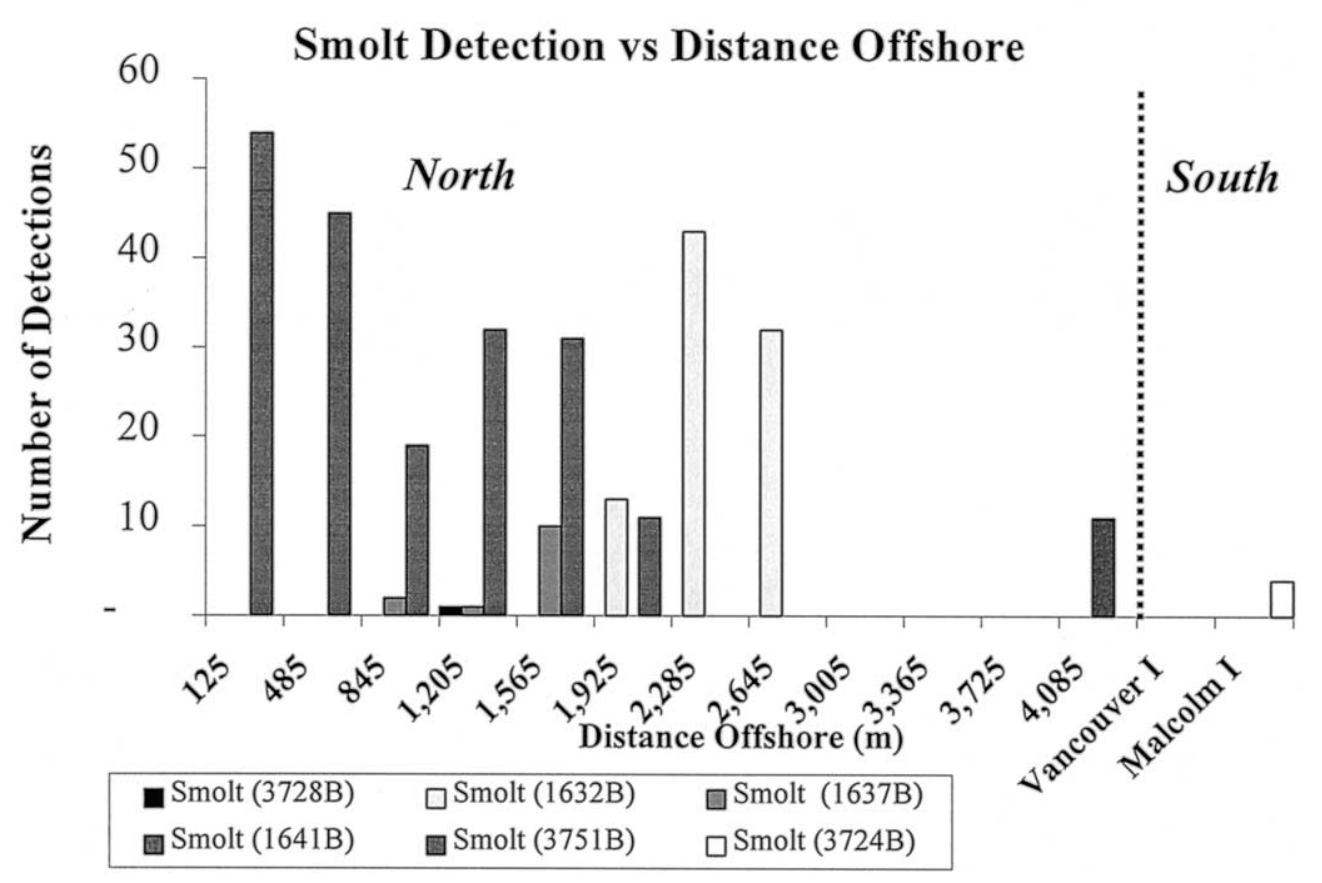

Fig. 7. Comparison of the pattern of detection of tagged steelhead smolts from the Keogh River on the detection lines in 2001. The $x$-axis shows the distance to the location of each array element relative to the Vancouver Island shoreline. The $y$-axis shows the number of discrete detections of each smolt recorded by the individual array elements. With the exception of one smolt (3728B), all animals were detected multiple times.

above the tide line. One kelt was also tagged with a slightly larger acoustic tag with an expected lifetime of ca. 15 months; it was detected when leaving the river, but was not detected in the ocean and is not further discussed.

A total of six smolts were subsequently detected in the ocean, with five detected on the acoustic detection line to the north of the mouth of the Keogh River, and one by the offshore receiver to the south. Several aspects of the ocean detections indicate that the smolts were neither orienting close to shore nor moving in a strongly directed fashion.

First, smolts were detected along the full length of the northern line which extended some $4 \mathrm{~km}$ offshore (Fig. 7), with one smolt detected on the outer edge. On the southern line, the single smolt detected to the south was recorded by the offshore receiver located close to Malcolm Island. As the northern line covered only the first four of the $21 \mathrm{~km}$ distance to the mainland, and the main channel lying between the eastern side of Malcolm Island and the mainland to the south was not covered at all in this trial deployment, the detection of six of 26 tagged smolts appears to be in rough proportion to detector coverage. Consequently, there is some reason to expect that smolt emigration out of Queen Charlotte Strait may be broadly distributed across the width of the Strait, with at least some smolts initially moving south.

Second, rates of movement of the smolts between receivers were quite low. The distance between the innermost receiver on the northern line and the mouth of the Keogh River was $8.5 \mathrm{~km}$, and the offshore receiver was located 9.5 $\mathrm{km}$ distant from the river mouth. The distance to the southern receiver was $16.3 \mathrm{~km}$. The four of five smolts detected on the northern line took 16.25, 23.5, 36.5, and $109.8 \mathrm{~h}$ from last detection in the river pool until first detection on the detection line (one smolt was not detected at the river mouth, but was subsequently detected on the array). This translates into a range of surprisingly low ground speeds when translated into body lengths per second $(0.08,0.11,0.35,0.46$, and $1.06 \mathrm{BL} / \mathrm{s})$.

The data become especially intriguing when the movement of one smolt (3751B) is analyzed in greater detail. This animal was first detected by the receiver closest to shore, on June $10^{\text {th }}$ at 10:10 AM, $23.5 \mathrm{~h}$ after last detection in the river, and was detected by the two receivers located within half a kilometer of shore for approximately $1.5 \mathrm{~h}$ (Fig. 7). The smolt was then re-detected on the array at a distance only slightly farther offshore on the afternoon of June 16th, $4.5 \mathrm{~d}$ later, when it was recorded on the next four of the offshore array elements for approximately $1 \mathrm{~h}$ before disappearing again. The array was removed from the water on June 21 st.

These two detections provide a very different perspective on the behavior of the same smolt. In the first case, the interpretation would be that this animal was migrating with considerable focus while orienting close to shore; it was detected on the nearshore receiver after moving at a mean speed of $0.46 \mathrm{BL} / \mathrm{s}$. However, the second detection $4 \mathrm{~d}$ later provides evidence for a different behavior; the mean speed now drops to only $0.08 \mathrm{BL} / \mathrm{s}$ and it was located close to where it was had first disappeared. The latter observations suggest an animal with little migratory focus. The resolution 
of this puzzling difference in behavior will only come with studies based on larger numbers of smolts, and demonstrates the potential value of developing a dedicated long-term acoustic tracking array.

The small-scale acoustic tracking study in 2001 was developed primarily to make some initial measurements on the movement of steelhead smolts in the ocean and gain some experience that would improve the planning for the larger study in 2002. The results have already provided some useful insight into the ocean biology of steelhead.

Prior to recovery of the acoustic array, an informal survey was made of the biologists and fishermen involved in the program, as to the expected behavior of the steelhead smolts in the ocean. All predicted that the smolts would be detected close to shore on the northern line soon after ocean entry, and then vanish from the study area; that is, we all expected that the smolts (and kelt) would turn sharply to the left and orient relative to the shore while moving north into their new habitat. The results indicate, however, that steelhead smolts may be occupying the inshore habitat of Queen Charlotte Strait for some significant period of time, and that their initial migration movements may not be as well focused or as near shore as had originally been suspected.

There is no prior information on the inshore movements of steelhead smolts after entering the ocean, so it is difficult to put the biological findings from the current very limited study into a broader context at this time. From tagging work using conventional numbered tags, there is evidence for steelhead moving north along the continental shelf migration path that the other species of Pacific salmon all seem to use as juveniles; however, there is also some evidence that at least some steelhead may move directly off the continental shelf to the open ocean (Hartt and Dell, 1986). The resolution to such questions awaits the development of a permanent continental-scale acoustic tracking array.

\section{References}

Arnold, G.P., Dewar, H., 2002. Electronic tags in marine fisheries research: a 30-year perspective. In: Sibert, J.R., Nielsen, J.L. (Eds.), Electron Tagging Track, Mar. Fish. pp. 7-64.

Block, B.A., Dewar, H., Farwell, C., Prince, E.D., 1998. A new satellite technology for tracking the movements of the Atlantic bluefin tuna. Proc. Natl. Acad. Sci. USA 95, 9384-9389.

Boehlert, G.W. (Ed.), 1997. Application of Acoustic and Archival Tags to Assess Estuarine, Nearshore, and Offshore Habitat Utilization and Movement by Salmonids. NOAA Technical Memorandum. NOAATM-NMFS-SWFSC-236. pp. 62.

Emery, K.O., 1980. Continental margins: classification petroleum prospects. Bull. Am. Assoc. Pert. Geol. 64, 297-315.

Groot, C., Margolis, L. (Eds.), 1991. Pacific Salmon Life Histories. UBC Press, Vancouver, pp. 564.

Hartt, A.C., Dell, M.B., 1986. Early oceanic migrations growth of juvenile pacific salmon steelhead trout. Int. North Pacific Fish. Comm. 46, $1-105$.

K. Khan, Maritime Boundaries. Globe. (August Issue; See http://www.defencejournal.com/globe/2000/aug/maritime.htm), 2000.
Lacroix, G.L., McCurdy, P., 1996. Migratory behaviour of post-smolt Atlantic salmon during initial stages of seaward migration. J. Fish. Biol. 49, 1086-1101.

Lacroix, G.L., Voegeli, F.A., 2000. Development of automated monitoring systems for ultrasonic transmitters. In: Moore, A., Russell, I. (Eds.), Fish Telemetry: Proceedings of the 3rd Conference on Fish Telemetry in Europe. CEFAS, Lowestoft, UK, pp. 37-50.

Lutcavage, M.E., Brill, R.W., Skomal, G.B., Chase, B.C., Howey, P.W., 1999. Results of pop-up satellite tagging of spawning size class fish in the Gulf of Maine: do North Atlantic bluefin tuna spawn in the mid-Atlantic? Can. J. Fisheries Aquat. Sci. 56, 173-177.

McGowan, G.E., 1993. Coastal Ichthyoplankton Assemblages with Emphasis on the Southern California Bight. Bull. Mar. Sci. 53 (2), $692-722$.

National Research Council, Illuminating the Hidden Planet, 2000. The Future of Seafloor Observatory Science. National Academy Press, Washington, D.C. p. 135.

Peterson, W.T., Miller, C.B., Hutchinson, A., 1979. Zonation maintenance of copepod populations in the Oregon upwelling zone. Deep-Sea Res. 26A, 467-494.

Quinn, T.P., 1993. A review of homing straying of wild hatchery-produced salmon. Fish. Res. 18, 29-44.

Quinn, T.P., Volk, E.C., Hendry, A.P., 1999. Natural otolith microstructure patterns reveal precise homing to natal incubation sites by sockeye salmon (Oncorhynchus nerka). Can. J. Zool. 77, 766-775.

Richardson, S.L., Laroche, J.L., Richardson, M.D., 1980. Larval fish assemblages associations in the northeast Pacific ocean along the Oregon coast winter-spring 1972-1975. Est. Coastal Mar. Sci. 11, 671-699.

Smith, B.D., Ward, B.R., Welch, D.W., 2000. Trends in wild adult steelhead (Oncorhynchus mykiss) abundance in British Columbia as indexed by angler success. Can. J. Fish. Aquat. Sci. 57, 255-270.

Tanaka, H., Takagi, Y., Naito, Y., 2000. Studies on the swim behaviour of chum salmon using micro data loggers in coastal waters. Nippon Suisan Gakkaishi. 66, 917-918.

Voegeli, F.A., Lacroix, G.L., Anderson, J.M., 1998. Development of miniature pingers for tracking Atlantic salmon smolts at sea. Hydrobiologia 371/372, 35-46.

Walker, R.V., Myers, K.W., Davis, N.D., Aydin, K.Y., Friedland, K.D., Carlson, H.R., Boehlert, G.W., Urawa, S., Ueno, Y., Anma, G., 2000. Diurnal variation in thermal environment experienced by salmonids in the North Pacific as indicated by data storage tags. Fisheries Oceanogr. 9, 171-186.

Ward, B.R., 2000. Declivity in steelhead trout recruitment at the Keogh River over the past decade. Can. J. Fisheries Aquat. Sci. 57, 298-306.

Welch, D.W., Eveson, J.P., 1999. An assessment of the geoposition accuracy of data storage (archival) tags using light. Can. J. Fish. Aquat. Sci. 56, 1317-1327.

Welch, D.W., Eveson, J.P., 2001. Recent progress in estimating geoposition using daylight. In: Sibert, J., Nielsen, J. (Eds.), Electronic Tagging and Tracking in Marine Fisheries. Methods and Technologies in Fish Biology and Fisheries. Kluwer Academic Press, Dordrecht, The Netherlands, pp. 369-384 vol. 1.

Welch, D.W., Batten, S.D., Ward, B.R., 00. Growth, survival, and rates of tag retention for surgically implanted acoustic tags in steelhead trout (O. mykiss). Trans. Am. Fish. Soc in press.

Welch, D.W., Ward, B.R., Smith, B.D., Eveson, J.P., 2000. Temporal spatial responses of British Columbia steelhead (Oncorhynchus mykiss) populations to ocean climate shifts. Fisheries Oceanogr. 9, 17-32.

Wiseman, J.D.H., Ovey, C.D., 1953. Definitions of features on the deep-sea floor. Deep-Sea Res. 1, 11-16. 